\title{
FENOMENA PENYESATAN DALAM TRADISI PRAKTIK PERTUNANGAN DI SAMPANG MADURA
}

\author{
Muqoffi \\ IAI Nazhatut Thullab Sampang \\ Email : muqoffi@gmail.com
}

\begin{abstract}
Abstrak:
Tunangan disyariatkan dalam Islam dengan cara dan pola tertentu agar menjadi pintu masuk yang tepat dalam menghindari disharmoni keluarga, baik dengan istri, mertua dan seluruh elemen rumah tangga. Namun dalam fakta sosial, praktik tunangan di masyarakat Sampang Madura banyak terjadi distorsi disebabkan penyesatan yang sistematis dan masif. Hasil penelitian menemukan setidaknya ada 5 penyesatan, yaitu: 1 . Penyesatan dalam memaknai tunangan. Sekket dan lamaran menjadi seremonial wajib untuk meresmikan ikatan tunangan. Sementara dalam Islam cukup kesepakatan melalui lisan dan dianjurkan merahasiakan status tunangan tersebut, bukan diviralkan dengan acara sekket dan lamaran, 2. Penyesatan konsep menerima tunangan. Mumpung laku dan takut sakkal sering menjadi alasan untuk menerima pinangan dari siapapun. Sedangkan dalam Islam calon yang agamanya baik dan berakhlak menjadi kriteria yang utama untuk menciptakan keluarga yang ideal, 3. Penyesatan tujuan menunangkan. Sebagai tameng dari hujatan dan agar menjadi jodoh banyak dijadikan tujuan menunangkan putranya. Tujuan yang justeru menjadi lumbung kemunkaran dan kerusakan keluarga, 4. Penyesatan budaya pertemuan dan 5. Penyesatan tradisi tukar cincin.
\end{abstract}

Kata Kunci: Penyesatan, Tunangan, Sampang

\begin{abstract}
:
Fiance is prescribed in Islam in certain ways and patterns so that it becomes an appropriate entrance in avoiding family disharmony, both with his wife, in-laws and all elements of the household. But in social facts, the practice of fiance in the Sampang Madura community is often distorted due to systematic and massive misdirection. The results of the study found that there were at least 5 deceits, namely: 1. Deception in interpreting fiance. Sekket and proposal become ceremonial mandatory to formalize the engagement. While in Islam it is quite an agreement through word of mouth and it is recommended to keep the status of the fiance a secret, not to be neutralized by a program of securities and applications, 2 . The misdirection of the concept of accepting a fiancée. While behavior and fear are often the reason to accept proposals from anyone. Whereas in Islam a candidate whose religion is good and moral is the main criterion for creating an ideal family. As a shield from blasphemy and in order to become a mate many used as the goal to get his son engaged. Precisely the aim of becoming a granary of confusion and damage to the family, 4. Misdirection of cultural encounters and 5. Misdirection of the tradition of ring exchange.
\end{abstract}

Keywords: Misdirection, Fiance, Sampang 


\section{Pendahuluan}

Pernikahan adalah ikatan sakral, suci dan sangat mulia di hadapan Allah Swt. Mereka yang menikah karena Allah Swt mendapat legitimasi istimewa dariNya sebagai ولاية الله (kekasih Allah Swt). Namun di balik itu, suami-istri memiliki tanggungjawab yang kompleks, berat dan penuh resiko. Resikonya bukan hanya di dunia tapi di akhirat bahkan Neraka. Karena setiap hak dan tanggungjawab yang tidak dijalankan dengan baik sesuai dengan tuntunan dan tuntutan syariat, maka Neraka ancamannya. Diantara persoalan besar yang banyak menimpa keluarga adalah tidak mampu mencari nafkah yang halal. Seperti yang dikemukakan oleh Imam al-Ghazaly dalam kitab monomentalnya. ${ }^{1}$

Karena itu, disyariatkan tunangan sebelum melangkah ke pelaminan sebagai upaya obyektif dan strategis dalam mengenal karakter dan hal ihwal dari pasangannya. Sehingga segala persoalan dan dinamika keluarga yang akan dihadapi nanti mampu diatasi dan ditanggulangi dengan baik. Namun dalam realitasnya masyarakat Sampang Madura banyak yang melakukan distorsi dan penyimpangan tunangan. Praktik tunangan yang sudah digariskan dalam Islam tidak menjadi rujukan primer bagi orang tua yang menunangkan anaknya, pemuda-pemudi yang bertunangan atau masyarakat sekitar yang ikut andil dalam proses pertunangan. Baik mereka yang memiliki latar belakang pendidikan madrasah, sekolah maupun pesantren. Apalagi mereka yang tidak belajar dan tidak mengenal sama sekali bangku pendidikan.

Dari tahapan awal sampai akhir pertunangan, masyarakat Sampang Madura mengarah kepada satu titik praktik sosial. Praktik yang salah dan melanggar aturan syariat tapi begitu masif dan sistematis, sehingga yang bertunangan terikat kuat untuk ikut melakukan dan mempraktikkannya. Hal itu karena apa yang mereka lakukan merupakan budaya lama yang mengakar kuat secara turun menurun dan tidak ada yang mampu merubahnya. Atau praktik baru yang dinilai trend day dan relevan dengan zamannya. Sehingga mereka mengklaim budaya itu sah-sah saja dilakukan dan tidak keluar dari batas kewajaran. Sebuah klaim santai tapi sebenarnya mematikan, karena menjadi media penyesatan kepada pemuda-pemudi untuk terus melakukannya. Mereka yang tidak berilmu, menjalankan budaya salah itu dengan rileks tanpa merasa bersalah, bahkan menikmati moment-moment tersebut dengan riang gembira. Tidak ada suara lantang yang mengganggu pesta pertunangannya. Tidak ada aksi yang mengusik kegembiraannya. Sementara mereka yang berilmu, tidak punya daya dan kuasa untuk menentang budaya tersebut. Karena keinginannya untuk mengikuti cara-cara Islami dalam bertunangan akan dikalahkan oleh kritikan yang masif di masyarakat Sampang Madura. Akan dikalahkan oleh penyesatan masyarakat yang tersembunyi dalam bingkai etika dan akhlak namun sebenarnya sebuah kemungkaran. Di hari raya misalnya, calon mertua dan seluruh keluarga menunggu kedatangan tunangan lakilaki untuk menjemput dan membawa putrinya bersafari ke tetangga dan sanak family. Kemudian dia datang dan membawa tunangannya yang notabene terjadi kemaksiatan, seperti sentuhan, ciuman atau bahkan perzinahan. Kalau tunangannya tidak datang, maka dianggap telah melakukan tindakan yang tidak wajar, tidak layak dan tidak benar. Para tetangga pun akan ikut mengutuk tindakan tersebut, karena

\footnotetext{
1 Imam Abi Hảmid al-Ghazảlî, Ihyả' 'Ulủm al-Dı̌n, Juz 2, (Kairo: Dâr al-Hadîts, 2004), 44.
} 
dinilai tidak bisa menjaga perasaan keluarga. Inilah penyesatan yang sistematis dan masif di masyarakat Sampang yang sampai saat ini sulit dirubah.

\section{Allah Swt berfirman:}

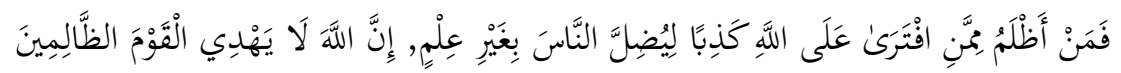

Artinya: Maka siapakah yang lebih dzalim daripada orang-orang yang membuat-buat dusta terhadap Allah untuk menyesatkan manusia tanpa pengetahuan?" Sesungguhnya Allah tidak memberi petunjuk kepada orang-orang yang dzalim (QS. al-A'raf : 37).

Dengan demikian, penelitian ini dirasa sangat penting agar penyesatan yang selama ini masif di masyarakat Sampang Madura bisa terbongkar ke permukaan dan mengetuk hati masyarakat untuk meninggalkan tradisi yang salah tersebut.

\section{Metode Penelitian}

Dalam penelitian ini peneliti menggunakan pendekatan kualitatif dalam rangka menemukan suatu kebenaran yang hakiki secara holistik dan dengan cara deskripsi dalam bentuk kata-kata. Sumber data penelitian diperoleh dari mudamudi masyarakat Sampang yang punya ikatan tunangan dan orang tuanya, seperti masyarakat Desa Daleman Kec. Kedungdung Kab. Sampang, masyarakat Desa Torjunan Kec. Robatal Kab. Sampang, masyarakat Desa Batuporo Timur Kec. Kedungdung Kab. Sampang dan Kec. Omben Kab. Sampang. Melului pengumpulan data kualitatif berupa wawancara, pengamatan atau observasi dan dokumentasi

\section{Penyesatan Sistematis dan Masif Dalam Praktik Tunangan di Sampang Madura}

Banyak muda-mudi Sampang Madura yang menjalani hubungan tunangan dengan cara menyimpang disebabkan penyesatan yang sistematis dan masif secara turun menurun. Peneliti berhasil menghimpun penyesatan-penyesatan sebagai berikut:

1. Penyesatan Makna Tunangan

Bagi masyarakat Sampang Madura tunangan diistilahkan dengan abekalan. Nama abekalan disematkan ketika sudah melakukan acara sekket atau lamaran. Makna sekket dan lamaran adalah: ${ }^{2}$

Sekket adalah acara pertemuan antarkedua keluarga, dimana pihak laki-laki membawa bingkisan yang bermacam-macam, seperti tettel, bechit, roti, pisang dan lain-lainnya, tapi tidak menyertakan beras. Acara sekket ini dilakukan setelah pernyataan untuk menikahi benar-benar diterima oleh wali wanita dalam acara masang ocak, sehingga aktivitas sekket merupakan seremonial lanjutan dari tahapan sebelumnya.

Lamaran ini sama dengan sekket, yaitu pertemuan antarkedua keluarga dengan membawa bingkisan. Hanya saja kalau lamaran disertai dengan pemberian beras dari pihak laki-laki kepada wanita. Sedangkan sekket tidak disertai beras. Sebelum acara sekket dan lamaran, ada acara ngin angin dan masang ocak. Makna ngin angin dan masang ocak adalah:

\footnotetext{
2 Wawancara langsung kepada Moh. Sodiq Desa Daleman Kec. Kedungdung Kab. Sampang pada 11 September 2019.
} 
Ngin Angin merupakan proses mencari informasi yang dilakukan oleh pihak laki-laki mengenai status wanita yang ingin dilamar, serta melihat peluang diterima tidaknya lamaran. Pada biasanya, pihak laki-laki melakukan pendekatan pada keluarga wanita atau rekan-rekannya.

Masang ocak ialah ucapan ingin menikahi dari pihak laki-laki kepada pihak wanita. Disampaikan sendiri atau yang mewakili kepada wali wanita. Ketika ucapan menikahi ini diterima oleh pihak wanita, maka dilanjutkan acara sekket atau lamaran.

Dalam konsensus masyarakat Sampang Madura, resmi disebut tunangan kalau sudah menjalani acara sekket atau lamaran. Tidak cukup dengan acara ngin angin atau masang ocak. Karena bagi mereka status tunangan harus ditandai dengan seremonial besar yang mempertemukan kedua keluarga dan tetangga sekaligus membagi-bagikan bingkisan yang dibawanya. Dengan demikian, makna tunangan versi masyarakat Sampang Madura tidak hanya sekedar ucapan tapi harus ada tanda atau diistilahkan dengan binsabin berupa pemberian. Makna yang sistematis ini begitu masif di kalangan masyarakat Sampang Madura sehingga semua kalangan memiliki pemahaman yang sama dari masa ke masa dan terus turun menurun sampai saat ini.

Hal ini merupakan penyesatan mengacu pada 2 argumentasi sebagai berikut: Pertama, dalam literatur fiqih yang resmi disebut tunangan itu kalau sudah disampaikan keinginan menikahi dari pihak laki-laki kepada wanita yang diinginkannya dan disepakati oleh wanita tersebut atau walinya. Dalam kitab Syarh al-Baijuri definisi tunangan adalah:

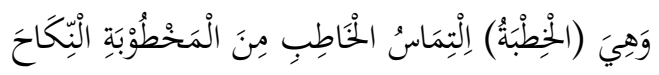

Artinya: Permohonan menikahi dari pelamar terhadap perempuan yang dilamar. ${ }^{3}$

Al-Zuhaily dalam al-Fiqih al-Islam wa Adillatihi menjelaskan, ketika permohonan dan pernyataan ingin menikahi itu disepakati oleh wanita yang dipinang atau oleh keluarganya, maka sudah sempurna dan resmi berstatus tunangan.

Dengan demikian, setelah acara masang ocak mereka sudah resmi disebut tunangan dan kemudian berlaku hukum-hukum yang berkaitan dengan tunangan. Diantaranya adalah haram dilamar dan dipinang orang lain. Sebagaimana hadits Nabi Muhammad Saw:

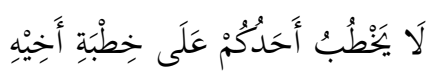

Artinya: Janganlah salah satu dari kalian melamar tunangan saudaranya. ${ }^{4}$

Belum adanya atau tidak adanya acara sekket atau lamaran tidak boleh dijadikan argumentasi oleh orang lain untuk tidak mengakui status tunangan. Bukan karena tidak ada tanda pemberian barang (binsabin) dari pihak pelamar kemudian tidak mengesahkan hubungan tersebut. Seperti yang kadang diutarakan oleh masyarakat Sampang Madura, "kata siapa dia tunangan, tandanya kan belum ada. Jangan salahkan yang mengganggu kalau belum ada tanda yang resmi”.

\footnotetext{
${ }^{3}$ Ibnu al-Qâsim al-Ghazzî, Hasyiah al-Syaikh Ibrâhîm al-Baijury Juz 2, (Lebanon: Dar al-Kitab alIlmiyah, 1971), 199.

${ }^{4}$ Sirâj al-Dîn Abî Hafsh, al-Badr al-Munîr, (t.t. Dar al-Hijrah li al-Nasyr wa al-Tauzi', t.t.), 519.
} 
Kedua, justeru acara sekket dan lamaran yang notabene mengandung fungsi menviralkan dan mengumumkan status tunangan itu merupakan tindakan yang menyimpang menurut hadits Nabi Muhammad Saw.

Nabi Muhammad Saw bersabda:

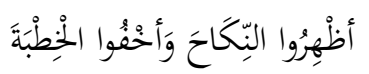

Artinya: Tampakkan pernikahan dan rahasiakan tunangan. ${ }^{5}$

Muhammad bin Ismail al-Amir al-Shan'ani mengemukakan alasan pentingnya merahasiakan status tunangan itu, yaitu agar tidak diganggu oleh mereka yang hasud. Karena hubungan tunangan merupakan bagian dari nikmat, sedangkan nikmat pasti akan dihasud. ${ }^{6}$

\section{Penyesatan Konsep Menerima Tunangan}

Orang tua wanita di kalangan masyarakat Sampang Madura banyak yang mudah menerima pinangan laki-laki. Sejalan dengan hasil observasi peneliti ke beberapa keluarga diketahui sangat mudah menerima ajakan tunangan dari seorang laki-laki meski mereka tidak tahu latar belakang kehidupannya secara jelas. ${ }^{7}$ Baik dari aspek nasab, pendidikan maupun akhlak sehari-hari. Setidaknya ada 2 kesalahan yang melatari tindakan mereka, yaitu:

Mumpung laku, Menurut para orang tua di masyarakat Sampang Madura, pihak wanita hanya bisa menunggu jodoh. Tidak bisa aktif mencari, memilih dan menentukan, sehingga ketika ada yang ingin meminang, maka langsung menarima menjadi pilihan yang menurutnya tepat.

Mempercayai ideologi sakkal adalah istilah masyarakat Sampang Madura yang memiliki arti kutukan tidak memperoleh jodoh selama-lamanya bagi wanita yang menolak pinangan. Begitulah hasil wawancara peneliti dengan beberapa masyarakat Sampang Madura. ${ }^{8}$ Dalam kepercayaan mereka, wanita tidak boleh selalu menolak pinangan, karena bisa berakibat mendapat kutukan sakkal. Sehingga dalam praktiknya mereka merasa harus menerima pinangan, baik pria yang meminangnya itu sesuai dengan kriteria Islam atau tidak. Kepercayaan itu didorong oleh beberapa kasus yang kebetulan tidak memperoleh pasangan karena pernah menolak ajakan pinangan dari seorang laki-laki.

Langkah para orang tua ini merupakan bentuk penyesatan yang begitu sistematis dan masif di kalangan masyarakat Sampang Madura, sehingga konsep yang benar menerima tunangan menurut Islam tidak banyak menjadi pijakan mereka. Dalam Islam, wali atau orang tua wanita diperintahkan untuk melihat dulu agama dan akhlak laki-laki yang hendak meminang agar mampu melaksanakan kewajiban rumah tangga, memenuhi hak-hak istri, mendidik anak, kepemimpinan yang baik, serta menjamin kebutuhan rumah, seperti nafkah, dan lain sebagainya. ${ }^{9}$

\footnotetext{
${ }^{5}$ Al-Azizy, Al-Sirâj al-Muň̆r Syarh al-Jâmi' al-Shaghı̆r (t.t. Mathba'ah al-Khairiyah, 1304 H.), 222.

6 Muhammad bin Ismail al-Amir al-Shan'ani, al-Tanwir Syarh al-Jâmi' al-Shaghı̆r Juz 2 (al-Riyadh: Maktabah Dar al-Salam, 2011), 447.

7 Wawancara langsung kepada Moh. Nurul Huda Desa Torjunan Kec. Robatal Kab. Sampang pada 15 September 2019.

8 Wawancara langsung kepada Ach. Siri pada 10 September 2019, kepada Moh. Nurul Huda pada 15 September 2019 dan kepada Ach. Rizal pada 20 September 2019.

${ }^{9}$ Abdullâh Nashih Ulwân, Adâb al-Khitbah wa al-Zifâf wa Huqủq al-Zaujain (t.t., Dar al-Salam, 1979), 33.
} 
Nabi Muhammad Saw bersabda:

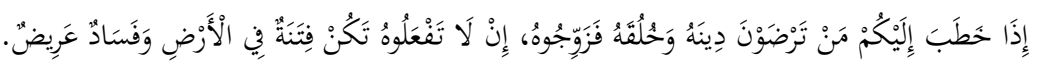

Artinya: Jika datang kepadamu orang yang kamu senangi dalam segi agama dan perangainya, maka hendaklah engkau mengawinkannya. Jika tidak, maka fitnahlah dan kerusakan besar yang timbul di muka bumi ini. ${ }^{10}$

Ketetapan untuk memilih calon suami ini sekaligus memberi legalisasi kepada pihak wanita untuk menolak pinangan laki-laki yang tidak seseuai dengan kriteria yang benar tanpa harus khawatir tidak laku atau mendapat kutukan sakkal. Ketika menolak itu diperbolehkan syariat bahkan diperintahkan, maka mereka yang menolak akan mendapat keuntungan bukan malah mendapat kerugian apalagi dikhawatirkan mendapat kutukan tidak laku dan sakkal. Sebuah ideologi yang tidak etis dan argumentatif. Bahkan sebaliknya, kalau mereka menerima pinangan dari laki-laki yang tidak baik, maka akan ada dampak negatif. Kitapun sadar banyak wanita baik kemudian menjadi buruk karena keburukan suami. Apalagi wanita buruk, maka akan lebih buruk karena keburukan suami.

Menolak pinangan boleh dan meminta untuk dipinang juga boleh bahkan sangat baik meminta dipinang kepada laki-laki ideal yang sesuai dengan kriteria Islam. Sesuai dengan jawaban Sahabat Anas dalam sebuah hadits Nabi Muhammad Saw:

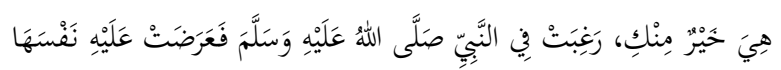

Artinya: wanita itu lebih baik dari kamu. Dia menyukai Nabi lalu menawarkan diri kepada Nabi. ${ }^{11}$

Bukan hanya wanita itu. Siti Khadijah sendiri juga menawarkan diri kepada Nabi Muhammad Saw untuk dinikahi. Begitu juga Sayyidina Umar Ra pernah menawarkan putrinya Hafshah kepada para sahabat. Dengan demikian, ungkapan "wanita hanya bisa menunggu jodoh" menjadi sesuatu yang tidak selamanya tepat bahkan bisa salah fatal. Karena pada dasarnya wanita dan laki-laki memiliki hak yang sama dalam memilih dan menolak calon tunangan.

Penyesatan ini tidak hanya menyesatkan masyarakat lain dalam memahami konsep menerima tunangan tapi juga menyesatkan kehidupan para anak-anak mereka dengan adanya suami yang tidak baik.

\section{Penyesatan Tujuan Menunangkan}

Hasil observasi peneliti menemukan banyak orang tua menunangkan anakanaknya dengan beberapa tujuan. ${ }^{12}$ Diantaranya adalah:

Sebagai tameng dari hujatan. Dalam realitanya, mereka yang saling cinta dan menjalin kasih dengan berpacaran banyak melakukan pelanggaran hukum agama, seperti jalan berduaan, melakukan pertemuan dan berbagai macam penyimpangan yang meresahkan masyarakat, sehingga kata hujatan, gunjingan dan penilaian negatif banyak terlontar dari masyarakat, khususnya dari kalangan kaum Hawa.

${ }^{10}$ Muhammad bin Abdi al-Hadŭ, Hâsyiah al-Sanadi Alâ Sunani Ibni Mâjah (Bairut: Dar al-Jail, 2010), 607.

${ }^{11}$ Muhammad bin Ismail al-Bukhari, Fath al-Bâri Juz 7 (Saudi Arabiyah: Amir Sulthan bin Abdu alAziz, t.t.), 80.

12 Wawancara langsung kepada Moh. Nurul Huda Desa Torjunan Kec. Robatal Kab. Sampang pada 15 September 2019. 
Hujatan ini tidak hanya dialamatkan kepada pasangan yang sedang memadu kasih tersebut tapi juga kepada orang tua dan keluarganya yang dinilai gagal memberi pengawasan dan bimbingan kepada anaknya. Dalam situasi ini, banyak orang tua di masyarakat Sampang yang kemudian memaksa mereka untuk bertunangan agar hujatan dan berbagai tudingan tersebut tidak lagi bermunculan. Karena para orang tua paham hujatan itu akan berakhir kalau status tunangan disematkan kepada mereka.

Dalam Islam, tunangan dilaksanakan dengan tujuan yang mulia dan cara yang benar, sebagaimana dijelaskan oleh Wahbah al-Zuhaily:

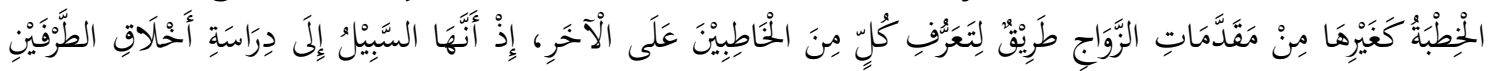

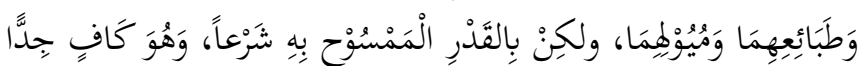

Artinya: khitbah seperti lainnya diantara langkah awal pernikahan adalah sebuah proses yang bertujuan saling mengenal antara satu dengan yang lain. Karena khitbah merupakan media mempelajari akhlak kedua belah pihak, karakter dan hasratnya, akan tetapi dengan kadar yang diperbolehkan oleh syara'. Dan itu sudah sangat cukup. ${ }^{13}$

Penyesatan tujuan menunangkan yang dilakukan para orang tua di masyarakat Sampang Madura ini selain karena tidak sesuai dengan tujuan islami juga disebabkan menyesatkan para anak untuk mudah melakukan kemaksiatan. Dalam observasi yang dilakukan peneliti kepada beberapa orang yang bertunangan tampak jelas mereka lebih bebas bertemu, memandang dan perbuatan dosa lainnya. Mereka yang awalnya merasa malu dan takut melakukan pelanggaran agama, kemudian menjadi berani setelah bertunangan. Karena hujatan yang biasanya ramai didengar di masyarakat sudah mulai senyap dan lenyap. Kalau dibahasakan lebih berani, tunangan itu hanya untuk investasi dosa dengan cara mudah, murah dan serba gratis. Dengan demikian dapat diambil benang merah bahwa tunangan yang sebenarnya sebagai media menjalankan perintah syariat, justeru mensyariatkan tunangan untuk melawan syariat.

Agar menjadi jodoh, tunangan kadang dijadikan cara untuk bisa berjodoh dengan wanita yang dicintainya. Dua sejoli yang menjalin hubungan asmara dengan status pacaran, teman tapi mesra, dan motif relasi asmara lainnya kemudian melakukan komitmen bersama untuk melanjutkan ikatan cintanya ke jenjang tunangan. Mereka sadar belum saatnya menikah tapi karena takut kala ngadek (diambil duluan oleh orang lain), khawatir diganggu orang lain dan agar benarbenar jodoh, maka mereka langsung bertunangan. Tradisi ini penulis istilahkan dengan memanipulasi jodoh.

Pada umumnya tradisi ini dilakukan oleh mereka yang usia muda, lebih-lebih yang masih berada di bangku sekolah dan dunia kampus. Sebuah hubungan yang harus mereka jalankan dalam waktu yang panjang antara 3-6 tahun bahkan lebih hanya karena ingin berjodoh. Pertanyaannya sekarang, apakah dengan segera bertunangan kemudian pasti menjadi jodohnya? Jawabannya belum tentu. Itu bisa dikategorikan sebuah ikhtiar dan usaha yang sangat mungkin gagal. Apalagi kita tahu jodoh di tangan tuhan dan sudah digariskan sebelum kita lahir ke dunia ini.

\footnotetext{
${ }^{13}$ Wahbah al-Zuhailî, al-Fiqhu al-Islảmı̆ wa adillatu, Juz 7 (Damaskus: Dâr al-Fikr, 1984), 10.
} 
Meski segera bertunangan mereka belum tentu berjodoh. Usahanya belum pasti berhasil. Yang pasti ada dan dialami adalah berbagai macam liku-liku dan problematika bertunangan, mulai gundah hati karena rindu ingin bertemu, pikiran tidak fokus karena ada dia dan harus melakukan banyak dosa karena praktik tunangan yang melanggar syariat. Sebuah persoalan besar yang harus ditanggung dalam waktu yang panjang sepanjang mereka tunangan untuk keuntungan yang belum tentu diraih.

\section{Penyesatan Budaya Pertemuan}

Dalam budaya masyarakat Sampang Madura, orang yang sudah tunangan dianggap wajar melakukan pertemuan, sehingga mereka kerap kali melakukan pertemuan secara terang-terangan di ruang publik maupun di tengah-tengah keluarga. Kadang yang laki-laki sengaja main-main ke rumah calon mertua dan kemudian melakukan pertemuan dengan tunangannya. Hal itu karena calon mertua memang memberi lampu hijau untuk bertemu, bertatap muka, bahkan berduaan. Apalagi ketika ada acara, seperti manten, tahlilan dan hajatan, maka tunangan menjadi salah satu tamu yang memang diharuskan datang secara adat, sehingga bertemulah dua sejoli tersebut. Lebih khusus di hari raya, maka pertemuan sudah sangat membudaya, bahkan calon mertua akan menilai negatif apabila calon menantunya tidak datang untuk menemui tunangannya, sehingga pertemuan di hari raya bukan hanya sekedar legal tapi sudah sampai pada batas wajib menurut mereka. Merupakan fakta yang tidak bisa dipungkiri, dalam pertemuan pasti ada tradisi salaman dengan calon mertua dan keluarga yang menurut mereka memiliki nilai yang baik bahkan menjadi barometer baik tidaknya moral tunangan, sehingga ketika tradisi ini tetap teguh dilakukan, maka klaim sopan dari masyarakat setempat dia dapatkan. Kalau sebaliknya, maka dia akan dinyatakan calon yang tidak beretika baik. Selain itu, setelah bertemu kemudian sering kali berlanjut pada acara jalanjalan, kencan dan berbagai tindakan amoral yang dapat dipastikan terjadi.

Budaya ini sebuah penyesatan yang sistematis dan masif. Menyesatkan mereka yang bertunangan untuk melakukan kemaksiatan dan menyesatkan para orang tua untuk membantu tindakan kemunkaran. Mereka seakan tidak berdaya untuk menghindari budaya tersebut. Karena sudah menjadi sistem bersama dan begitu kuat. Dalam Islam, pertemuan itu masuk dalam kategori ikhtilath atau khalwat (berduaan) yang diharamkan. Status tunangan tidak menghalangi hukum haram melakukan pertemuan. Karena secara fiqih, mereka masih tergolong haram bertemu tanpa disertai mahram sebagaiamana orang lain yang tidak berstatus tunangan.

\section{Penyesatan Tradisi Tukar Cincin}

Seremonial tukar cincin sudah menjadi tradisi di kalangan milenial masyarakat Sampang Madura khususnya di level elit. Dalam tahapannya, pihak lakilaki membawa bingkisan untuk diberikan kepada calon wanita. Kemudian calon laki-laki menyatakan kata pinangan kepada calon wanita yang dilanjutkan dengan tukar cincin emas dari kedua pasangan secara bergantian.

Menurut mereka seremonial ini sangat perlu diadakan sebagai tanda resmi dan kuat bahwa mereka benar-benar berstatus sebagai tunangan. Pemakaian cincin 
tersebut sekaligus melambangkan rasa cinta dan kasih sayang serta kesiapan untuk melangkah ke jenjang pernikahan, sehingga cincin tunangan selalu dipakai oleh kedua pasangan dimanapun, khususnya di acara-acara besar yang memungkinkan dilihat orang lain.

Dalam diteratur Islam, tradisi tukar cincin ini adalah tindakan yang menyimpang dari ketentuan hukum syari'at, dilihat dari beberapa faktor:

Keharaman cincin emas bagi laki-laki, Cincin emas haram dipakai laki-laki. Begitu juga cincin emas yang dipakai laki-laki ketika acara tunangan. Karena cincin itu tidak hanya dipakai ketika prosesi tunangan tapi pasca acara terus dipakai dalam waktu yang lama bahkan sampai pernikahan, maka keharamannya juga dalam waktu yang lama setiap kali dipakai dan digunakan. Selain itu, dalam prosesi tukar cincin terdapat sentuhan antara kedua pasangan yang sulit dihindari yang notabene diharamkan dalam perspektif agama Islam, baik bagi yang wanita maupun yang pria.

Taklid Buta dan Tasyabbuh Kepada Yahudi dan Nasrani. Tukar cincin tunangan merupakan seremonial taklid buta dan tasyabbuh kepada budaya Yahudi dan Nasrani, sebagaimana disampaikan oleh Abdullah Nashih Ulwan dalam Adab alKhitbah wa al-Zifaf wa Huquq al-Zawjaini. ${ }^{14}$

\section{Urgensi Merubah Penyesatan Dalam Praktik Tunangan di Sampang Madura}

Setiap penyesatan, kemunkaran dan kemaksiatan perlu dirubah ke arah yang baik. Merubah penyesatan yang sistematis dan masif dalam praktik tunangan di Sampang Madura ini menjadi sesuatu yang sangat urgen dan vital. Karena merupakan maksiat yang tampak di tengah-tengah masyarakat. Fakta berbicara bahwa mereka lalu lalang di sekitar kita dalam melakukan pelanggaran etika dan kode etik tunangan, seperti bersepeda, jalan berdua, tukar cincin dan bersalaman kepada yang bukan mahram. Mereka bak pemain Bollewood yang acting kemesraan di tengah-tengah penonton yang asyik menyaksikan alur ceritanya.

Nabi Muhammad Saw bersabda:

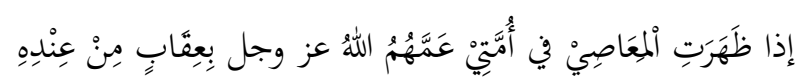

Artinya: Kalau jelas kemaksiatan pada ummatku, maka Allah meratakan siksaan kepada semuanya. ${ }^{15}$

Selain itu, setiap dosa tidak boleh diremehkan termasuk dosa tunangan. Nabi Muhammad Saw mengajarkan kita untuk menjauhi dosa-dosa kecil. Karena bila berkumpul pada seseorang akan menghancurkan dirinya. Sehingga pada akhirnya bisa mengahancurkan pokok keimanan. Karenanya, bila seorang menganggap remeh dosa kecil maka imannya sudah terkontaminasi dan hilanglah kehormatannya karena selalu menganggap kecil segala sesuatunya. Bukankah banyaknya dosa kecil bisa menjadi malapetaka. Dan bukankah menganggap remeh dosa kecil akan menjadi dosa besar di hadapan Allah Swt.

Oleh sebab itu, maka pintarlah untuk memilah-milih mana yang hak dan mana yang batil. Terlebih kepada mereka yang terkenal mempunyai ilmu, maka mempraktikkan gaya tunangan modern yang menyalahi aturan syariat bisa

\footnotetext{
${ }^{14}$ Abdullâh Nashih Ulwân, Adab al-Khitbah wa al-Zifaf, 57.

15 Muhammad Nasib al-Rifâ'I, Taisir al-Ali al-Qadir, (al-Riyadh: al-Maktabah al-Ma'arif, 1989), 283.
} 
berdampak pada berlipat gandanya dosa. Karena apa yang mereka lakukan akan dicontoh dan diteladani oleh masyarakat umum, khususnya pengikut dan fansnya. Sehingga ketika praktik tunangan yang salah itu dilakukan oleh mereka yang berilmu maka akan dijadikan dalil pembenaran oleh masyarakat untuk mengikuti jejak langkahnya. Kritikan dari orang lain tidak akan mampu merubah konsep berpikirnya. Karena kritikus yang tidak ahli di bidang agama dianggap tidak punya otoritas untuk menghakimi tindakannya.

Sedangkan dalam al-Qur'an, Allah Swt berfirman:

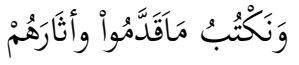

Artinya: Saya tulis apa yang sudah mereka lakukan dan bekas-bekas mereka (QS. Yasin : 12).

Dalam Audhah al-Tafsir dijelaskan arti ayat ini bahwa amal baik kita akan dicatat sekaligus amal baik mereka yang meneladani kita. Sebaliknya, amal buruk kita dicatat sekaligus amal buruk mereka yang mengikuti kita. ${ }^{16}$ Dengan demikian, kalau yang melakukan pelanggaran tunangan itu adalah mereka yang berilmu, maka dosanya berlipat ganda. Dosa dari kesalahannya sendiri dan dosa dari mereka yang mengikutinya. Kalau yang mengikuti banyak, maka beban dosanya semakin banyak. Bahkan terancam mendapat siksaan yang paling pedih di hari kiamat. Sebagaimana sabda Nabi Muhammad Saw :

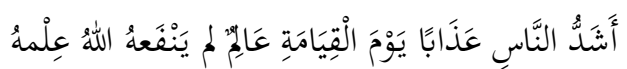

Artinya: paling keras siksaan seseorang di hari kiamat adalah orang berilmu yang tidak nafi' ilmunya. ${ }^{17}$

Oleh sebab itu, kemunkaran tunangan ini harus ditinggalkan, karena kalau tetap kita biarkan dan tidak ada pendekatan preventif, maka kita semua akan dapat getahnya. Sejalan dengan pernyataan Imam Ghazaly:

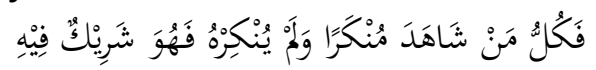

Artinya: Setiap orang yang menyaksikan kemungkaran dan tidak mengingkarinya, maka dia tergolong didalamnya. ${ }^{18}$

Jadi, bukan cara yang tepat kalau kita mendukung distorsi tunangan. Bukan pula sikap yang bijaksana kalau kita rela dengan pelanggaran tersebut. Etika yang benar adalah mengingkari, menolak dan merubah budaya yang buruk menjadi budaya yang islami. Karena distorsi tunangan ini tidak hanya menjadi keburukan bagi pelakunya, tapi juga menjadi catatan hitam bagi seluruh masyarakat sekitar. Sehingga membasmi mafsadah 1 orang yang bertunangan, sama halnya menyelamatkan banyak orang dari ancaman dosa, siksaan, malapetaka dan kehancuran.

Tradisi (urf) masyarakat perihal praktik tunangan tidak bisa dijadikan alibi untuk melegitimasi distorsi dan penyimpangannya. Karena urf yang bertentangan dengan syara' tidak bisa dijadikan pijakan hukum. Dalam al-Mausu'ah al-Fiqihiyyah dipaparkan:

\footnotetext{
16 Muhammad Abdu al-Lathĭf al-Khatı̆b, Audhah al-Tafâs̆̌r Juz 1, 536.

17 Muhammad Abdu Al-Rouf al-Munâwy, Al-Taišrr bi Syarhi al-Jâmi' al-Shaghı̆r Juz 1 (Lebanon: Dar al-Kutub al-Ilmiyah, 1971), 400.

18 Al-Munảwŭ. Faid al-Qad̆̌r, juz I (Bairut: Dâr al-Ma'rifah, 1972), 493.
} 


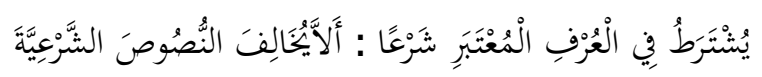

Atinya: Urf yang dianggap dalam syara' syaratnya tidak boleh bertentangan dengan nash syara'.19

\section{Kesimpulan}

Hasil penelitian menemukan banyak penyesatan yang sistematis dan masif di masyarakat Sampang Madura mengenai praktik tunangan. 1. Penyesatan dalam memaknai tunangan. Sekket dan lamaran menjadi seremonial wajib untuk meresmikan ikatan tunangan. Sementara dalam Islam hanya membutuhkan kesepakatan melalui lisan, bahkan tradisi ini merupakan bentuk menampakkan ikatan tunangan yang sebenarnya menurut Islam perlu dirahasiakan, 2. Penyesatan konsep menerima tunangan. Mumpung laku dan takut sakkal menjadi alasan yang menurutnya tepat untuk menerima pinangan. Sedangkan dalam Islam ada kriteria khusus pinangan bisa diterima, 3. Penyesatan tujuan menunangkan. Sebagai tameng dari hujatan dan agar menjadi jodoh menjadi tujuan menunangkan putranya. Tujuan yang berimplikasi menimbulkan kemunkaran, 4. Penyesatan budaya pertemuan dan 5. Penyesatan tradisi tukar cincin.

Penyesatan ini sangat urgen dirubah ke arah yang baik. Karena merupakan maksiat yang tampak di tengah-tengah masyarakat, sehingga yang bertanggungjawab bukan hanya pelaku tapi semua orang yang menyaksikan dan mendukungnya. Tradisi (urf) masyarakat perihal praktik tunangan tidak bisa dijadikan alibi untuk melegitimasi distorsi dan penyimpangannya. Karena urf yang bertentangan dengan syara' tidak bisa dijadikan pijakan hukum.

\section{Daftar Pustaka}

Nashih Ulwân, Abdullâh. 1979. Adâb al-Khitbah wa al-Zifâf wa Huqủq al-Zaujain. t.t. Dar al-Salam,

Al-Azizy. 1304 H. Al-Sirâj al-Munĭr Syarh al-Jâmi' al-Shaghı̆r . t.t. Mathba'ah alKhairiyah.

Al-Munảwı̆. 1972. Faid al-Qadǐr, juz I. Bairut: Dâr al-Ma'rifah.

al-Ghazzî, Ibnu al-Qâsim. 1971. Hasyiah al-Syaikh Ibrâhîm al-Baijury Juz 2. Lebanon: Dar al-Kitab al-Ilmiyah.

al-Ghazảlî, Imam Abi Hảmid. 2004. Ihyả' 'Ulủm al-Dĭn, Juz 2. Kairo: Dâr al-Hadîts. al-Khatı̌b, Muhammad Abdu al-Lathŭf. Audhah al-Tafâš̌r Juz 1.

al-Munâwy, Muhammad Abdu Al-Rouf. 1971. Al-Taišrr bi Syarhi al-Jâmi' al-Shaghı̆r Juz 1. Lebanon: Dar al-Kutub al-Ilmiyah.

al-Hadŭ, Muhammad bin Abdi. 2010. Hâsyiah al-Sanadi Alâ Sunani Ibni Mâjah. Bairut: Dar al-Jail.

al-Shan'ani, Muhammad bin Ismail al-Amir. 2011. al-Tanwir Syarh al-Jâmi' alShaghĭr Juz 2.al-Riyadh: Maktabah Dar al-Salam.

al-Bukhari, Muhammad bin Ismail. t.t., Fath al-Bâri Juz 7. Saudi Arabiyah: Amir Sulthan bin Abdu al-Aziz.

19 Wizârah al-Auqâf wa al-Syu'ûn al-Islâmiyah, al-Mausû'ah al-Fiqhiyah al-Kuwitiyyah, Juz 30. (Kuwait: Dzât al-Salâsil, 1986), 58. 
al-Rifâ'i, Muhammad Nasib. 1989. Taisir al-Ali al-Qadir. al-Riyadh: al-Maktabah alMa'arif.

Abî Hafsh, Sirâj al-Dîn. t.t. al-Badr al-Munîr. t.t. Dar al-Hijrah li al-Nasyr wa al-Tauzi'. al-Zuhailî, Wahbah. 1984. al-Fiqhu al-Islảmı̆ wa adillatu, Juz 7. Damaskus: Dâr alFikr.

Wizârah al-Auqâf wa al-Syu'ûn al-Islâmiyah. 1986. al-Mausû'ah al-Fiqhiyah alKuwitiyyah, Juz 30. Kuwait: Dzât al-Salâsil. 